\title{
Work in Progress: The Effect of Immersive Design-Build Experiences on Knowledge of the Engineering Design Process
}

\section{Dr. William H. Guilford, University of Virginia}

Will Guilford is an Associate Professor of Biomedical Engineering at the University of Virginia. He is also the Undergraduate Program Director for Biomedical Engineering, and the Director for Educational Innovation in the School of Engineering and Applied Science. He received his B.S. in Biology and Chemistry from St. Francis College in Ft. Wayne, Indiana and his Ph.D. in Physiology from the University of Arizona. Will did his postdoctoral training in Molecular Biophysics at the University of Vermont under David Warshaw. His research interests include novel assessments of educational efficacy, the molecular basis of cell movement, and the mitigation of infectious diseases.

Miss Anna S. Blazier, University of Virginia

Alyssa B. Becker, University of Virginia 


\section{Work in Progress: The Effect of Immersive Design-Build Experiences on Knowledge of the Engineering Design Process}

Knowledge of the engineering design process is integral to all engineering fields. Explicit didactic approaches exist for instilling students with this knowledge (see an excellent review by Dym, et al. ${ }^{1}$ ), and project-based learning (PBL) is typically part of any given instructional blend. However, one can also use immersive, hands-on design-build activities to implicitly deliver knowledge of the engineering design process ${ }^{2}$.

We sought to answer two questions: (a) can a course that immerses students in iterative physical construction of student designed devices, rather than classroom activities, improve knowledge of the engineering design process, and (b) does a learning environment that also emphasizes academic advising further bolster this knowledge? So-called "intrusive advising" is believed to increase academic performance and persistence in majors (reviewed in Banta et al. ${ }^{3}$ ).

Course design and interventions: Our study was reviewed and found exempt by our Social and Behavioral Sciences Institutional Review Board (project \# 2014-0302-00). Two sections of a first-year introduction to engineering course were studied in two successive years (totaling 4 sections). The same instructor taught all four sections; thus any differences we observed would most likely be due to the intervention. We introduced two interventions: (a) to engage all the students in an intensive design-build experience to covertly deliver knowledge of the engineering design process, and (b) to engage half the students in intrusive advising.

The instructor served as the academic advisor for each of the students in advising-intensive (advised) sections. He met with them individually, required that they each attend five events to expand their utilization of campus resources, and incorporated several in-class discussions on topics including pedagogy, choosing major, academic advising, preparing for a career, stress management, and support resources.

In the non-advised section, students spent an equivalent amount of time in weekly team progress meetings. The instructor and teaching assistants spoke with each group independently for about 8 minutes to see how their team was functioning, what progress they had made, what materials they might need, to give advice on their design, and to encourage brainstorming where appropriate. In the first year of intervention, the non-advised group was taught first, followed by the advised section. In the second year of intervention the order was reversed.

Regardless of section, the students were divided into teams of 5-7 students using CATME ${ }^{4}$ and were challenged to envision and build products to solve an everyday problem. Many chose BME-related problems, though this was not required. Product concepts resulting from these problems ranged from a device for detecting when a patient leaves their bed in a clinical care setting, to a device to relieve a specified amount of weight from a patient during physical therapy. They subsequently engaged in two rounds of design, prototyping, and testing to ensure that they experienced iteration in the design process. At each stage of design - from conceptualization, to the initial and final prototypes - students maintained electronic lab books and made presentations. Along the way the students were taught CAD, were introduced to shop safety, and were required to use a variety of tools including table saws, band saws, drill presses, grinders and sanders, sewing machines, microcontrollers, laser cutters, and 3D printers (these most commonly used). 
These intensive design-build activities lasted for $6-8$ weeks of the $\sim 14$ weeks of instruction, including one round of design and construction iteration. Thus, the hands-on emphasis was unusually high. At the end of the course, each team generated an invention disclosure report in the format for submission to the University's office governing intellectual property, including comprehensive CAD drawings of their product.

Delivery of the assessments: A test of engineering design process knowledge designed by others ${ }^{5}$ was delivered on paper twice - once at the beginning and once at the end of the semester - in class, and timed by the instructor. Briefly, this instrument challenged students to examine a Gantt chart representing a design process, and identify things that were "good" or "correct" about the process as depicted, and things that were "bad" or "incorrect" about the process. Knowledge was assessed in seven knowledge domains, and scored 0-2 in each domain:

1. Identification of needs,

2. Idea generation,

3. Analysis and decisions,

4. Building and testing,
5. Timing and duration of activities,

6. Layout of a design process with iteration, and

7. Documentation.

In the 20 minutes immediately before the beginning-of-semester assessment was delivered, students were given an introduction to Gantt charts using a real world example. Only a brief reminder of the structure of a Gantt chart was given prior to the end-of-semester assessment. Students were asked to work on this assignment for 10 minutes.

Results and discussion: The advised sections of the course totaled 70 students over two years, while the non-advised sections totaled 76 . There were no significant differences in scores between the two years over which this study was conducted, suggesting that the sequence in which the sections were taught was not a significant factor in the outcome. Students' knowledge of the design process was highest in the domains of idea generation (brainstorming), building and testing, iteration and layout of the design process, and time allocation (see below table). In fact, students' time allocation scores were perfect both at the beginning and the end of the class.

\begin{tabular}{|c|c|c|c|c|c|c|c|c|c|}
\hline & & Needs & Ideas & Analysis & Build & Layout & Time & Document & Total \\
\hline \multirow{3}{*}{ 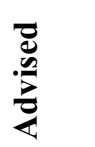 } & Begin & $0.40 \pm 0.09$ & $1.2 \pm 0.1$ & $0.49 \pm 0.08$ & $1.25 \pm 0.06$ & $1.64 \pm 0.07$ & $2 \pm 0$ & $0.9 \pm 0.1$ & $7.8 \pm 0.3$ \\
\hline & End & $0.39 \pm 0.08$ & $1.3 \pm 0.1$ & $0.36 \pm 0.08$ & $1.19 \pm 0.05$ & $1.57 \pm 0.08$ & $2 \pm 0$ & $1.3 \pm 0.1$ & $7.9 \pm 0.3$ \\
\hline & $\mathbf{p}$ & 0.9 & 0.5 & 0.3 & 0.4 & 0.5 & - & 0.001 & 0.8 \\
\hline \multirow{3}{*}{ 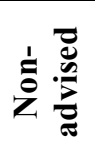 } & Begin & $0.33 \pm 0.07$ & $1.25 \pm 0.10$ & $0.26 \pm 0.06$ & $1.21 \pm 0.06$ & $1.47 \pm 0.08$ & $2 \pm 0$ & $0.8 \pm 0.1$ & $7.3 \pm 0.2$ \\
\hline & End & $0.32 \pm 0.08$ & $1.36 \pm 0.09$ & $0.28 \pm 0.07$ & $1.20 \pm 0.05$ & $1.72 \pm 0.06$ & $2 \pm 0$ & $1.3 \pm 0.1$ & $8.1 \pm 0.2$ \\
\hline & $\mathbf{p}$ & 0.8 & 0.4 & 0.9 & 0.8 & 0.008 & - & $<0.001$ & 0.004 \\
\hline
\end{tabular}

There were significant differences between the advised and non-advised sections of the course (see gray shaded cells in the above table). While the advised sections showed gains only in the domain of documentation, the non-advised group showed gains in documentation, layout and iteration, and total knowledge.

The greater improvement of the non-advised section over the advised section was perhaps due to repetitive brainstorming during the weekly team meetings, while the advised section was deprived of this activity. Work by others suggests that repetitive brainstorming improves self- 
efficacy ${ }^{8,9}$ - people's beliefs in their capacities to produce desired effects through their actions ${ }^{10}$. We hypothesize that the construct of self-efficacy is covariate with actual process knowledge, and that process knowledge is improved through brainstorming. The latter may be tested by measuring whether knowledge of processes other than engineering design can be covertly influenced by brainstorming, but without overt instruction on that process.

These data are consistent with a previous study showing that the mode of instruction (textbook design projects, product archaeology, or service learning design projects) makes no difference to the accumulation of design process knowledge, nor do any of these modes actually lead to a measurable increase in total knowledge ${ }^{6}$. The mode of instruction reported in the present study most closely resembles an internship; internships have been found to specifically increase documentation knowledge, as we saw here, while regular engineering classes fail to cause such an increase, even over the span of an entire degree curriculum ${ }^{7}$.

Not only were there few significant improvements in process knowledge, but also the degrees of improvement were relatively small. Among the possible explanations for this are (a) failure of the immersive experiences to covertly deliver process knowledge, (b) that the instrument is not an accurate measurement of process knowledge, (c) that the instrument is overly sensitive to context, and (d) that the additional priming before the first measurement biases the instrument. Context is almost certainly a factor, since the creators of the instrument found that the design problem prompt has a significant effect on the outcome of the instrument, even if the Gantt chart itself remained the same ${ }^{6}$. Further, others used this instrument and found positive results ${ }^{11}$, suggesting again that context matters. Future work will focus on creating an alternative measure of engineering design process knowledge.

1. Dym CL, Agogino AM, Eris O, Frey DD, Leifer LJ. Engineering Design Thinking, Teaching, and Learning. J Eng Educ. 2005 Jan 1;94(1):103-20.

2. Guilford WH, Blazier AS, Becker A. Integration of Academic Advising into a First-year Engineering Design Course and Its Impact on Psychological Constructs. In: Proceedings of the 2015 ASEE Annual Conference and Exposition. Seattle; 2015. p. Paper \#13507.

3. Banta TW, Hansen MJ, Black KE, Jackson JE. Assessing Advising Outcomes. NACADA J. 2002 Mar 1;22(1):5-14.

4. Layton R, Loughry ML, Ohland MW, Ricco GD. Design and Validation of a Web-Based System for Assigning Members to Teams Using Instructor-Specified Criteria. Adv Eng Educ. 2010;2(1):1-28.

5. Bailey R, Szabo Z. Validation of Approaches to Assess Design Process Knowledge. In: Proceedings of the 2005 American Society for Engineering Education Annual Conference \& Exposition. 2005.

6. Ernst N, Brickley S, Bailey R, Cornia J. Effects of First-Year Engineering Design Course Models on Student Design Process Knowledge. In: Frontiers in Education Conference, 36th Annual. 2006. p. 7-12.

7. Bailey R. Where do Students Learn about Engineering Design? In: Frontiers in Education Conference, 36th Annual. 2006. p. 1-6.

8. Sewell A, St George A. Developing efficacy beliefs in the classroom. J Educ Enq. 2000;1(2):58-71.

9. Gist ME. The Influence of Training Method on Self-Efficacy and Idea Generation Among Managers. Pers Psychol. 1989;42(4):787-805.

10. Bandura A. Self-Efficacy: The Exercise of Control. Macmillan; 1997. 628 p.

11. Saterbak A, Volz T. Assessing Knowledge and Application of the Design Process. In 2014 [cited 2016 Jan 28]. p. 24.203.1-24.203.13. Available from: https://peer.asee.org/assessing-knowledge-and-application-of-thedesign-process 